\title{
Research on Effectiveness and Operational Monitoring after Adding Passivator in Transformers
}

\author{
Qian Yihua ${ }^{1, a^{*}}$, Zeng Shufang ${ }^{2, b}$, Zhao Yaohong $^{1}$, Cao Shun'an ${ }^{2}$ \\ 1.Electric Power Research Institute of Guangdong Power Grid Corporation , Guangzhou , \\ Guangdong, China \\ 2.School of Power and Mechanical engineering , Wuhan University , Wuhan, Hubei, China \\ a382685248@qq.com, b445298130@qq.com.
}

Keywords: Transformers, Corrosive sulfur, passivator, operational monitoring Abstract: After adding passivators in corrosive sulfur-containing transformers, conducted follow-up research and monitoring on the effectiveness and comsumption of passivator, and monitor the quality of transformer oil after adding passivator, which aims to provide a reference for the operational monitoring after adding passivator and is of great significance to the safe and stable operation of the power grid. The research has shown that the passivator can effectively protect the copper wire from corrosive sulfur, the oil quality and chromatographic trace results were normal, and transformers ran normally and stably.

\section{Introduction}

In recent years, transformer faults caused by corrosive sulfur occurred frequently in home and abroad, which brought great damage to the safe operation of power grid[1-2]. Researchers proposed to add metal passivators to solve this problem[3-4]. The mechanism of metal passivator is that it reacts with copper to form a protective film, thus to prevent the reaction of copper and corrosive sulfur, as shown in Figure 1[5]. Passivator will runs out due to the aging of oil or other reasons, so these problems may occur again. At present, there is no research on the effectiveness and operating monitoring of passivator in China.
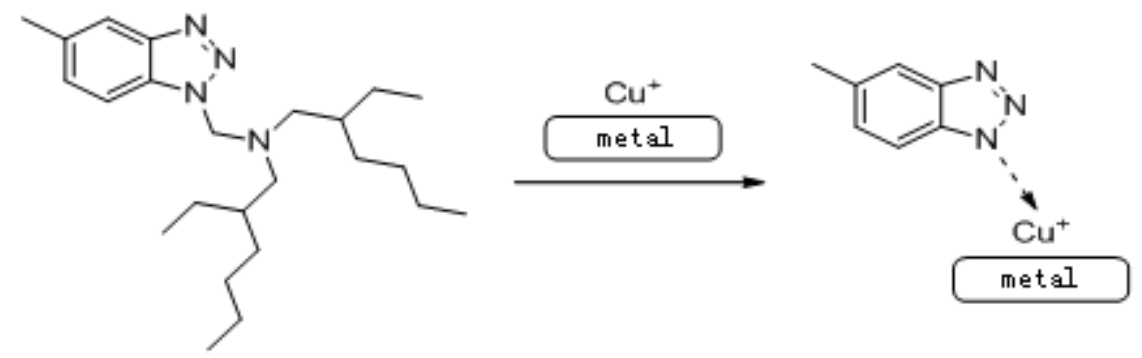

Figure 1 Mechanism of metal passivators

Since 2006, Guangdong Power Grid has added passivator in 243 transformers, and these transformers run normally now. However, as for the follow-up problems such as the influence of passivator on oil and transformers, whether to add passivator again, we need to research and solve these probelems. Based on the consideration, our team added $100 \mathrm{mg} / \mathrm{kg}$ passivator Irgamet 39 in 14 transformers containing less than $5 \mathrm{mg} / \mathrm{kg}$ Irgamet 39 according to the IEC operation and maintenance guidelines, and conducted research on the operating monitoring of the 17 transformers, 
including test the electrical, chemical and physical properties of oil, the concentrations of Irgamet 39 and dibenxyl fisulfide (DBDS), and chromatographic analysis etc., to monitor the effectivenss and consumption of passivator. We selected $3110 \mathrm{kV}$ transformers (Sanzhong\#1,Shuibei\#2 and Shuibei\#3) as focus objects to monitor the quality of oil and provide references for the operation of transformers containing passivator.

\section{Operational monitoring of transformer oil}

\section{Consumpation of passivator and concentration changes of DBDS}

In the case that temperature of oil is stable, the consumption of passivator is shown in Table 1 and Figure 2, concentration changes of DBDS are shown in Figure 3.

Table 1 Consumption of passivator Unit: $\mathrm{mg} / \mathrm{kg}$

\begin{tabular}{ccccccccc}
\hline $\begin{array}{c}\text { Time/month } \\
\text { Name }\end{array}$ & Before & 1 & 2 & 3 & 4 & 5 & 6 & 7 \\
\hline Sanzhong\#1 & none & 104.8 & 100.7 & 99.21 & 96.78 & 95.08 & 90.16 & 81.13 \\
Shuibei\#2 & None & 79.02 & 73.80 & 68.72 & 65.64 & 61.02 & 54.89 & 44.54 \\
Shuibei\#3 & none & 86.29 & 81.39 & 76.96 & 73.32 & 66.22 & 58.36 & 48.60 \\
\hline
\end{tabular}

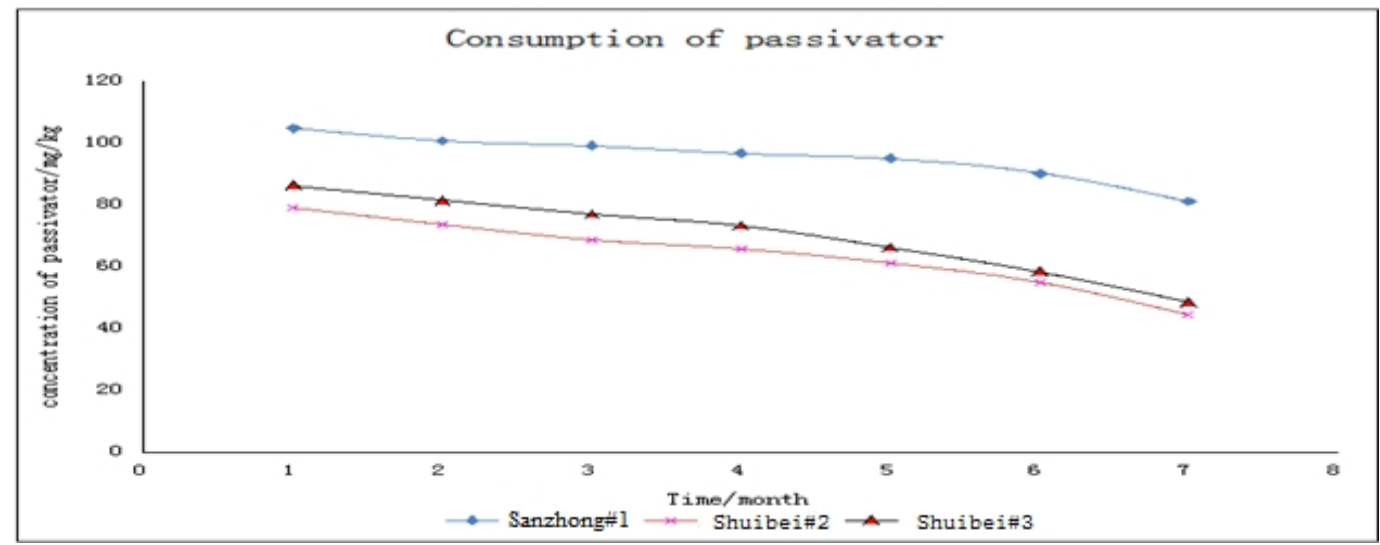

Figure 2 Consumption of passivator

From Table 2, we can see that the content of passivator in oil decreases with the time goes, and the monthly consumption amount is about $2-10 \mathrm{mg} / \mathrm{kg}$, and the average monthly consumption amount is about $6 \mathrm{mg} / \mathrm{kg}$. With the operation time of transformer, the consumption amount became larger, and this is because the oil became easier to be oxidized due to the consumption of antioxidant, so the rate of consumption increased.

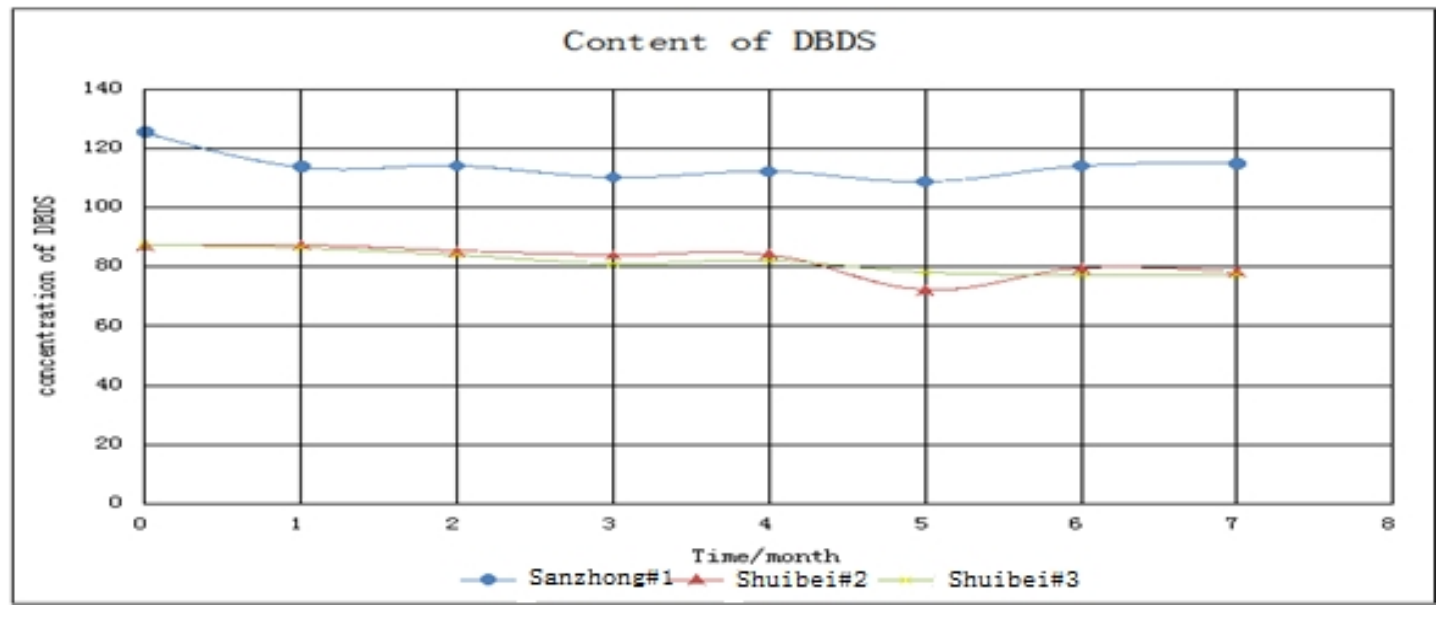

Figure 3 Concentration of DBDS 
From Figure 3, we can see the DBDS remained basically unchanged,in 3 transformers, so we think that the DBDS did not react with the copper, which indicates that the passivator has effectively protected the copper to some extent.

\section{Changes of the electrical properties of transformer oil}

\section{Changes of breakdown voltage}

Breakdown voltage is often used to measure the withstand voltage capability of oil. The changes of breakdown voltages in 3 transformers are shown in Figure 4. After monitoring the breakdown voltages for several months, the breakdown voltages basically remained stable, so we think that the breakdown voltage will not be influenced by the passivator.

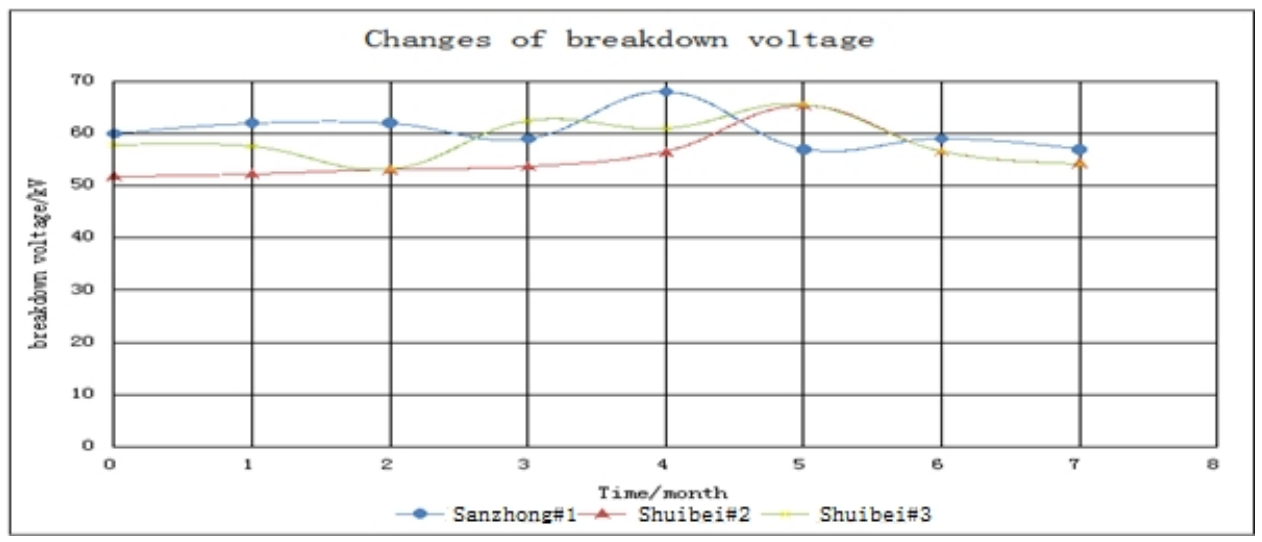

Figure 4 Changes of breakdown voltage

\section{Changes of dielectric loss factor}

$\tan \delta$ is called dielectric loss factor, and will increase due to polar impurities or colloidal substances. The changes of $\tan \delta$ is shown in Figure 5. The values of $\tan \delta$ of the 3 transformers basically kept stable at early stages, which indicates that the oil did not become impure. And they became a little larger at later stages, this is because the oils were aged gradually, but there is no evidence that the passivator has influenced the oil.

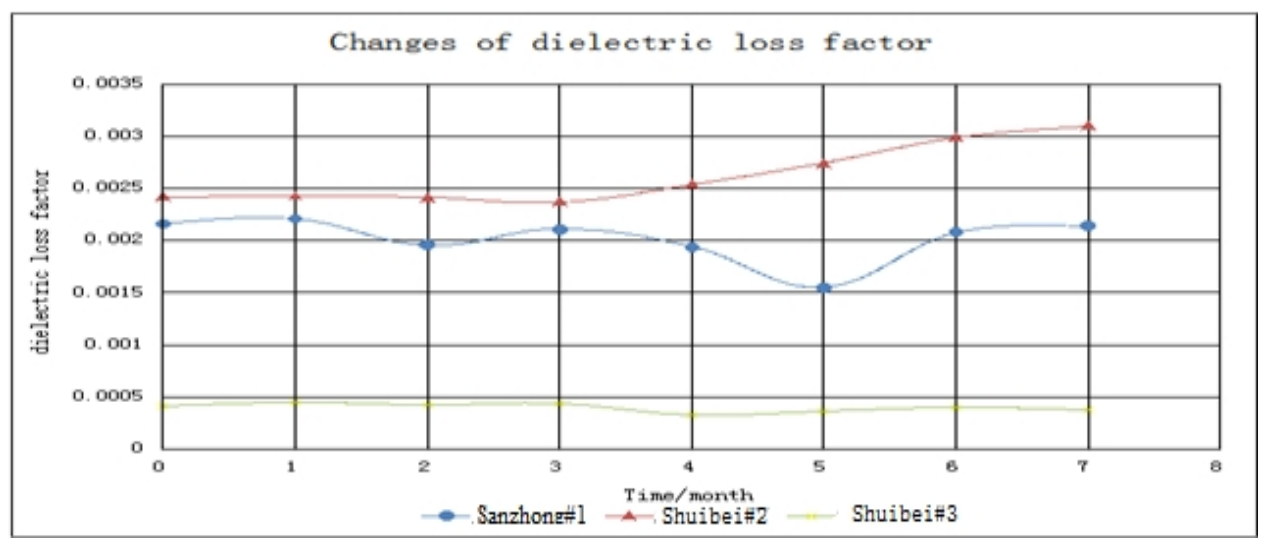

Figure 5 Changes of dielectric loss factor

\section{Changes of volume resistivity}

Volume resistivity reflects the dielectric property of the oil, and is sensitive to the water content, impurities and acidic products in oil, and will decrease if the oil is contaminated by these substances. The changes of volume resistivity is shown in Figure 6. We can see that the values of the volume resistivity waved slightly, but basically kept stable, so we think that the passivator has no side effects on volume resistivity. 


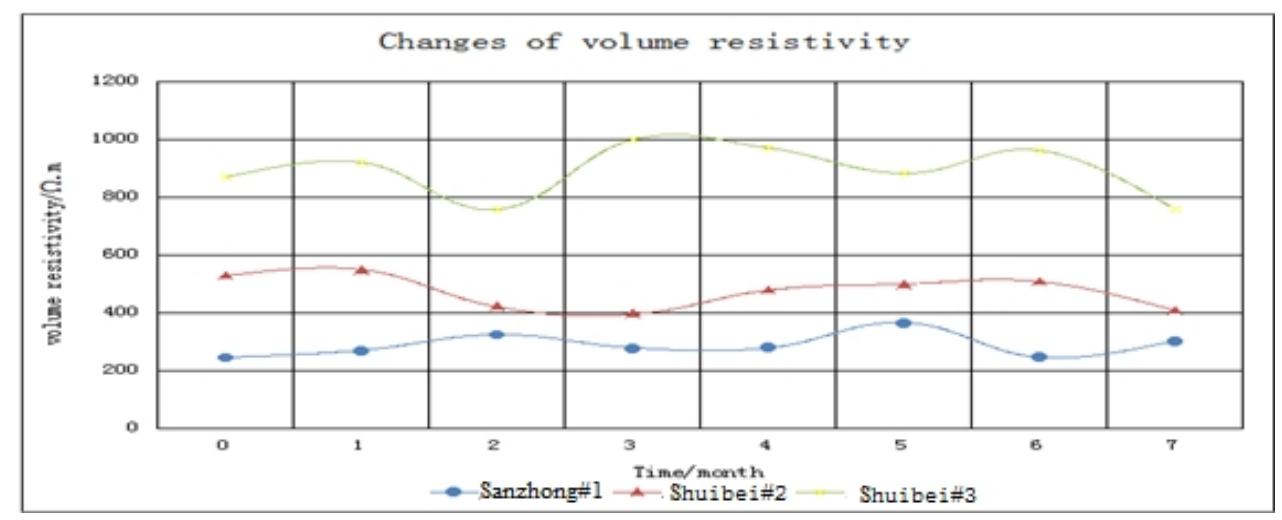

Figure 6 transformer oil volume resistivity changes

\section{Changes of physical and chemical properties of transformer oil}

Changes of particle, sludge and sediment, flash point and interfacial tension

According to the results of the operational monitoring of the 3 transformers, the particle size, interfacial tension and flash point remained basically unchanged, and they are within acceptable limits, wherein the changes of interfacial tension are shown in Table 2. Also no sludge and precipitate appeared.

Table 2 Changes of interfacial tension unit: $\mathrm{mN} \cdot \mathrm{m}-1$

\begin{tabular}{ccccccccc}
\hline Time/month & Before & 1 & 2 & 3 & 4 & 5 & 6 & 7 \\
Name & & & & & & & & \\
\hline Sanzhong\#1 & 45.4 & 41.7 & 45.7 & 42.1 & 41.5 & 41.3 & 40.7 & 42.4 \\
Shuibei\#2 & 43.1 & 45.2 & 49.3 & 48.2 & 46.0 & 47.5 & 48.3 & 47.2 \\
Shuibei \#3 & 46.6 & 46.5 & 49.6 & 46.3 & 47.0 & 48.2 & 46.9 & 47.8 \\
\hline
\end{tabular}

\section{Changes of acid value and $\mathrm{pH}$}

After adding the passivator, $\mathrm{pH}$ values were between 6.0-6.8 (neutral), and the acid values of the 3 transformers are shown in Table 3. Acid value of oils increased slightly due to the aging of oil, and passivator did not have bad effects on the acid value.

Table 3 transformer oleic acid value variation

Unit: $\mathrm{mgKOH} / \mathrm{g}$

\begin{tabular}{ccccccccc}
\hline $\begin{array}{c}\text { Time/month } \\
\text { Name }\end{array}$ & Before & 1 & 2 & 3 & 4 & 5 & 6 & 7 \\
\hline Sanzhong\#1 & 0.002 & 0.002 & 0.002 & 0.005 & 0.005 & 0.005 & 0.005 & 0.007 \\
Shuibei\#2 & 0.001 & 0.001 & 0.002 & 0.002 & 0.002 & 0.002 & 0.004 & 0.005 \\
Shuibei\#3 & 0.001 & 0.001 & 0.002 & 0.004 & 0.004 & 0.004 & 0.004 & 0.005 \\
\hline
\end{tabular}

\section{Antioxidants and furfural products in transformer oil}

The research also monitored the content of antioxidants in oil, the results showed that antioxidant continued to decrease gradually. Furfural products are used as an important basis for judging the aging extent of paper insulation, and were not detected in oil, that is to say, the passivator did not affect the paper insulation and continue to consume antioxidants, decreased gradually. During operation monitoring period, furfural was also not detected in oil, indicating that the passivator did not affect the aging status of paper insulation in transformers to some extent.

\section{Chromatographic trace results}

In this research, we also monitored the chromatographic analysis of the 17 transformers. And herein we select Sanzhong\#1 as an example to show the chromatographic trace results. In Table 4, 
we can see that the chromatographic trace results kept stable, indicating that the transformers runs well and no furfural appeared, so we think the passivator did not have side effects on the aging status of oil.

Table 4 Chromatography track results of Sanzhong\#1 unit: $\mu \mathrm{L} / \mathrm{L}$

\begin{tabular}{ccccccccc}
\hline Time/month & $\mathrm{H}_{2}$ & $\mathrm{CH}_{4}$ & $\mathrm{C}_{2} \mathrm{H}_{4}$ & $\mathrm{C}_{2} \mathrm{H}_{6}$ & $\mathrm{C}_{2} \mathrm{H}_{2}$ & $\mathrm{CO}$ & $\mathrm{CO}_{2}$ & $\begin{array}{c}\text { Total } \\
\text { hydroca } \\
\text { rbons }\end{array}$ \\
\hline Before & 2.85 & 17.93 & 3.98 & 5.64 & 0 & 892 & 5548 & 27.550 \\
1 & 2.66 & 18.87 & 5.70 & 4.20 & 0 & 967 & 5678 & 28.77 \\
2 & 2.85 & 17.29 & 5.70 & 4.11 & 0 & 834 & 6136 & 27.10 \\
3 & 1.98 & 17.93 & 5.61 & 3.89 & 0 & 849 & 5035 & 27.43 \\
4 & 1.81 & 18.66 & 5.78 & 3.94 & 0 & 729 & 5047 & 28.38 \\
5 & 1.9 & 19.25 & 5.89 & 4.29 & 0 & 712 & 5263 & 29.43 \\
6 & 2.16 & 20.17 & 6.58 & 4.57 & 0 & 737 & 5322 & 30.7 \\
7 & 2.85 & 17.93 & 3.98 & 5.64 & 0 & 892 & 5548 & 27.550 \\
\hline
\end{tabular}

\section{Conclusions}

According to the follow-up research and monitoring after adding passivator, we can draw the following conclusions:

1) After adding passivator, passivator was gradually consumed, the monthly consumption amount remained at $2-10 \mathrm{mg} / \mathrm{kg}$, the average monthly consumption amount was $6 \mathrm{mg} / \mathrm{kg}$, and this data can be used as a reference for census cycle of passivator.

2) After adding passivator, conten of DBDS in oil remained basically unchanged, indicating that DBDS did not react with copper and the passivator can effectively alleviate the corrosion of DBDS.

3) According to the oil quality tracking data and chromatographic trace data, adding passivator has little influence on the electrical, physical and chemical properties of transformer oil, and it can be ignored.

4) After adding the passivator, furfural was not detected in oil, did not affect the aging status of paper insulation in transformers to some extent.

\section{References :}

[1] Scatiggio F, Tumiatti V, Maina, et al Corrosive Sulfur in Insulating Oils:. Its Detection and Correlated Power Apparatus Failures [J] IEEE Transactions on Power Delivery, 2008,23 (1): 508-509.

[2] Qian Yi-hua, Hu Honghong, Yao Weijian, Analysis and Treatment of Transformer Fault Caused by Corrosive Sulfur[J]. Transformer, 2008,45 (1): 28-30.

[3] Cao Shun'an, Li Rui, Qian Yihua Overview of Research on Corrosive Sulfur in Transformer Oil [J] Power Plant Chemistry, 2008,10 (8):.. 481-486.

[4]Tang Feng, Liu Xiangping. Causal Investigation into Typical Faults of Main Transformers and Corresponding Precautions[J]. Guangdong Electric Power, 2008,21 (12): 77-79.

[5]Qian Yi-hua. Protection Technology of Corrosive Sulfur in Mineral Insulating Oils Used for 
International Forum on Energy, Environment Science and Materials (IFEESM 2015)

Power Equipment[M]. Beijing: China Electric Power Press, 2013. 